Lara Lázaro Touza*

Gonzalo Escribano Francés ${ }^{* *}$

Virginia Crespi de Valldaura***

\title{
TRANSICIÓN ENERGÉTICA Y GOBERNANZA CLIMÁTICA EN TIEMPOS DE PANDEMIA
}

La pandemia del COVID-19 ha alterado las expectativas acerca de la transición energética, acentuando las tendencias subyacentes previas a la misma. La gobernanza climática también se ha visto afectada por el COVID-19 en un año clave para elevar la ambición. Aunque la prioridad de gobiernos y ciudadanos sea la lucha contra el virus, este cambio radical en el contexto a corto plazo no debe distraer de los retos que plantean la transición energética y la gobernanza climática a medio y largo plazo.

\section{Energy transition and climate governance in times of pandemic}

The COVID-19 pandemic has altered the expectations regarding the energy transition, enhancing pre-existing trends. Climate governance has also been affected by COVID-19 in a key year for increasing ambition. While the priority of governments and citizens is the fight against the coronavirus, the radical change in the short-term context should not distract us from the challenges brought about by the energy transition and climate governance in the medium and long term.

Palabras clave: transición energética, COVID-19, gobernanza climática.

Keywords: energy transition, COVID-19, climate governance.

JEL: Q20, Q35, Q40, Q54.

\footnotetext{
* Programa de Energía y Clima, Real Instituto Elcano. Profesora de Teoría Económica del Centro de Enseñanza Superior Cardenal Cisneros (adscrito a la UCM). Contacto: llazaro@rielcano.org

** Programa de Energía y Clima, Real Instituto Elcano. Profesor Titular de Economía Aplicada, UNED. Contacto: gescribano@rielcano.org

*** Programa de Energía y Clima, Real Instituto Elcano.

Contacto: v.crespi-de-valldaura@Ise.ac.uk

El presente artículo traduce y actualiza parte de un documento de trabajo y un comentario publicado por el Real Instituto Elcano con las siguientes referencias:

Escribano, G., \& Lázaro, L. (2020). Oil markets, energy transition, climate governance and COVID-19: the short, the medium and the long term. Real Instituto Elcano (article WP 6/2020 - 22/04/2020). Lázaro, L. y Escribano, G. (2020). Desde España para Europa: propuestas para una recuperación verde a la crisis del COVID-19. Real Instituto Elcano (comentario 17/2020 - 18/5/2020).

Versión de septiembre de 2020.

https://doi.org/10.32796/ice.2020.916.7101
} 


\section{Introducción}

La crisis del coronavirus ha transformado completamente el contexto global, y los ámbitos de la energía y el clima no han sido una excepción. Se ha apuntado que la crisis del coronavirus nos ha situado «en una situación de incertidumbre radical, que además puede alargarse en el tiempo» (Steinberg, 2020). En cierta medida, este análisis puede entenderse como una enmienda casi a la totalidad de las conjeturas sobre la posible evolución de los ámbitos de la energía y la lucha contra el cambio climático realizadas a principios de año. Casi, pues si bien el panorama a corto plazo ha mutado al ritmo del virus, los retos de la transición energética y la lucha contra el cambio climático permanecen inalterables (Escribano, 2020; Lázaro, 2020). El artículo reflexiona sobre las distintas fases de la respuesta a la crisis del COVID-19: la respuesta inmediata a la crisis sanitaria y el impacto de esta sobre el sector energético y la gobernanza climática; la contención a corto y medio plazo de la crisis y las sendas que el sector energético ofrece para la recuperación económica; y la transformación del modelo económico en el más largo plazo, pero con implicaciones inmediatas. El artículo concluye con unas reflexiones preliminares sobre el papel de las políticas energética y climática en esos tres horizontes temporales.

\section{La transición energética y COVID-19: tendencias globales, la UE, EE UU y China}

\section{Tendencias globales}

Del corto al medio plazo, uno de los riesgos más citados de la pandemia de COVID-19 para el sector energético es su impacto sobre el sector de las energías renovables y, en consecuencia, sobre el ritmo de la transición energética. La caída de los precios del gas y del petróleo podría hacer perder competitividad-precio a las energías renovables, y desincentivar la inversión en las mismas por parte de los gobiernos y del sector privado a nivel global y regional. La evolución del precio de los derechos de emisión del $\mathrm{CO}_{2}$ en la UE ilustra este desincentivo. El Gráfico 1 muestra cómo el precio de los derechos se hundió y luego rebotó, pasando de 25,59 euros a finales de febrero a 15,24 euros a mediados de marzo para luego subir a 29,23 euros el 9 de julio de 2020, acercándose a los 30,5 euros de finales de junio de 2008 y superando los 29,03 euros de finales de julio de 2019. Esta caída de marzo de 2020 sin duda supuso un desincentivo a la reducción de emisiones. Sin embargo, cabe esperar que la reforma del régimen de comercio de derechos de emisión de la UE y la introducción en el 2019 de la reserva de estabilidad de mercado limiten una caída duradera del precio del $\mathrm{CO}_{2}$.

Además de esta distorsión de los incentivos económicos que afecta a la transición energética, la propia crisis sanitaria y económica corre el riesgo de distraer a los gobiernos, en cuyas agendas será complicado priorizar cualquier otro tema. Pueden generarse así retrasos administrativos y políticos, además de una mayor competencia por captar partidas del presupuesto. A nivel global, el comportamiento de los mercados de capitales en lo relativo a la financiación de inversiones en energías renovables será una de las variables a observar de cerca para poder comprender el impacto de la pandemia en la transición ecológica. A ello se une la posible ralentización (o disrupción), en principio temporal, de la cadena de suministro global de las renovables (Temple, 2020). La importancia de China en su cadena de valor ha tenido un impacto especialmente importante sobre el sector renovable en todo el mundo, con el consiguiente riesgo añadido de retrasos en la ejecución de los proyectos (Hallack \& Yepez, 2020).

Aunque se espera que el impacto de la pandemia sea comparativamente menor en las energías renovables que en las energías fósiles, pueden anticiparse varios efectos negativos a corto plazo. Así, son previsibles retrasos en el lanzamiento de nuevas subastas. Dichas subastas han supuesto un aumento significativo en la inversión a unos precios cada vez más 


\section{GRÁFICO 1}

EVOLUCIÓN DEL PRECIO DE LOS DERECHOS DE EMISIÓN EN LA UE, 2008-2020 (En $€ / E U A)$

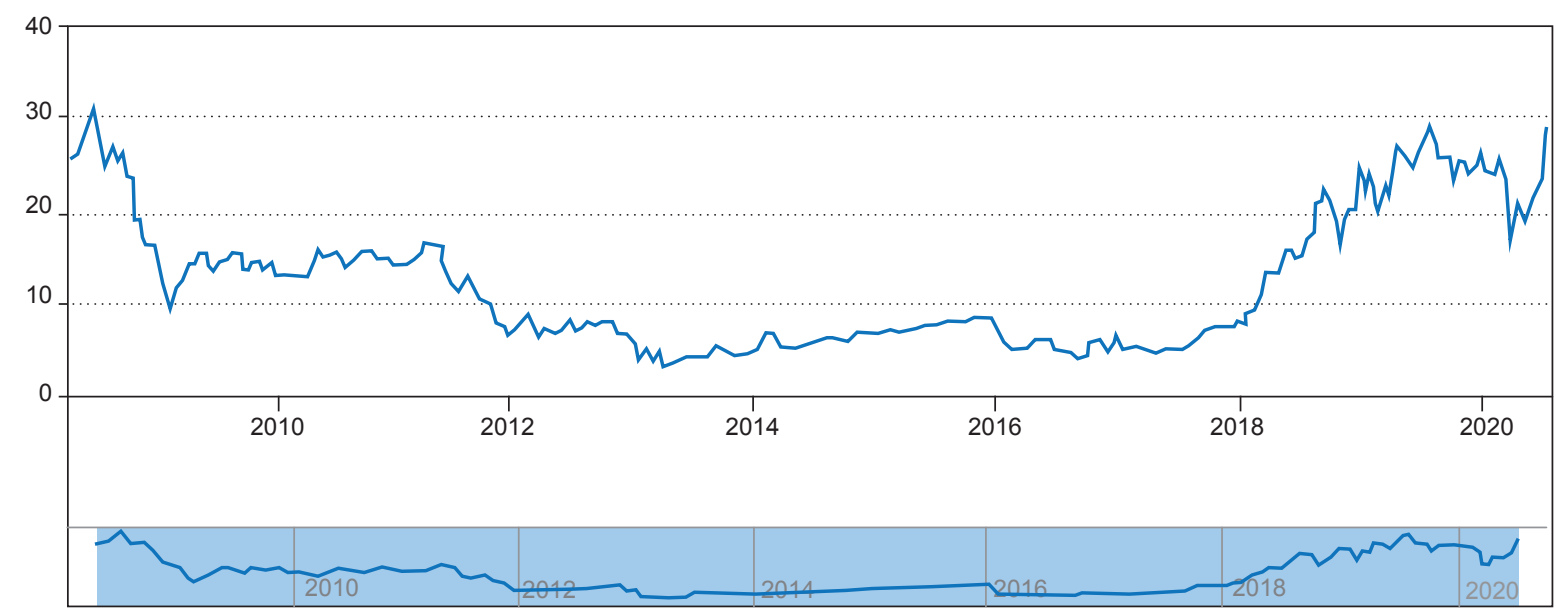

NOTA: Periodo que comprende del 07.04.2008 al 09.07.2020.

FUENTE: EMBER, Carbon Price viewer. https://ember-climate.org/carbon-price-viewer/

competitivos frente a la generación de energía eléctrica con hidrocarburos y con energía hidráulica. Otro riesgo potencial es el descenso a corto plazo de la financiación para nuevos proyectos renovables, que dependerá mucho de la duración de la crisis sanitaria y de los recursos que consuma, así como de su impacto sobre la demanda eléctrica. Las empresas de renovables también afrontan un mayor riesgo si los acuerdos de venta de electricidad, Power Purchase Agreements (PPAs), están fijados en monedas locales que pueden verse afectadas por devaluaciones o si el comprador es una empresa pública con problemas financieros que pueda llegar a entrar en mora (Viscidi \& Graham, 2020).

Teniendo en cuenta el contexto actual, la Agencia Internacional de la Energía (AIE) prevé una reducción de la instalación de potencia eléctrica renovable de un $13 \%$ en 2020 en comparación con 2019, recuperándose en 2021 pero alcanzando un nivel un $10 \%$ menor en comparación con las estimaciones previas a la crisis del COVID-19 para 2021 (IEA, 2020) (Gráfico 2).
Las empresas, por su parte, pueden retrasar las decisiones de mitigación y adaptación al cambio climático, aun cuando su exposición al riesgo en esta materia se mantenga en esencia inalterado. Por ejemplo, a corto plazo, las aerolíneas europeas y el sector automovilístico están presionando a la Comisión para que retrase las reformas del régimen de comercio de derechos de emisión, que incluirían a los sectores difusos ${ }^{1}$, así como la revisión en 2021 de los objetivos de emisiones de los coches (Khan, 2020). Otros sectores también insisten en que se aplique el principio de neutralidad tecnológica en la investigación y el desarrollo, por ejemplo en lo que concierne a la captura y almacenamiento de carbono (CAC) y las soluciones de hidrógeno. Algunas industrias altamente contaminantes, como lo son la petroquímica y la farmacéutica, están aprovechando para

\footnotetext{
1 Los sectores difusos son aquellos que no están sujetos al régimen de comercio de derechos de emisión e incluyen: el sector residencial, comercial e institucional $(\mathrm{RCl})$, transporte, agricultura y ganadería, gestión de residuos, gases fluorados e industria no incluida en el régimen de comercio de derechos de emisión de la UE (EU ETS, por sus siglas en inglés).
} 


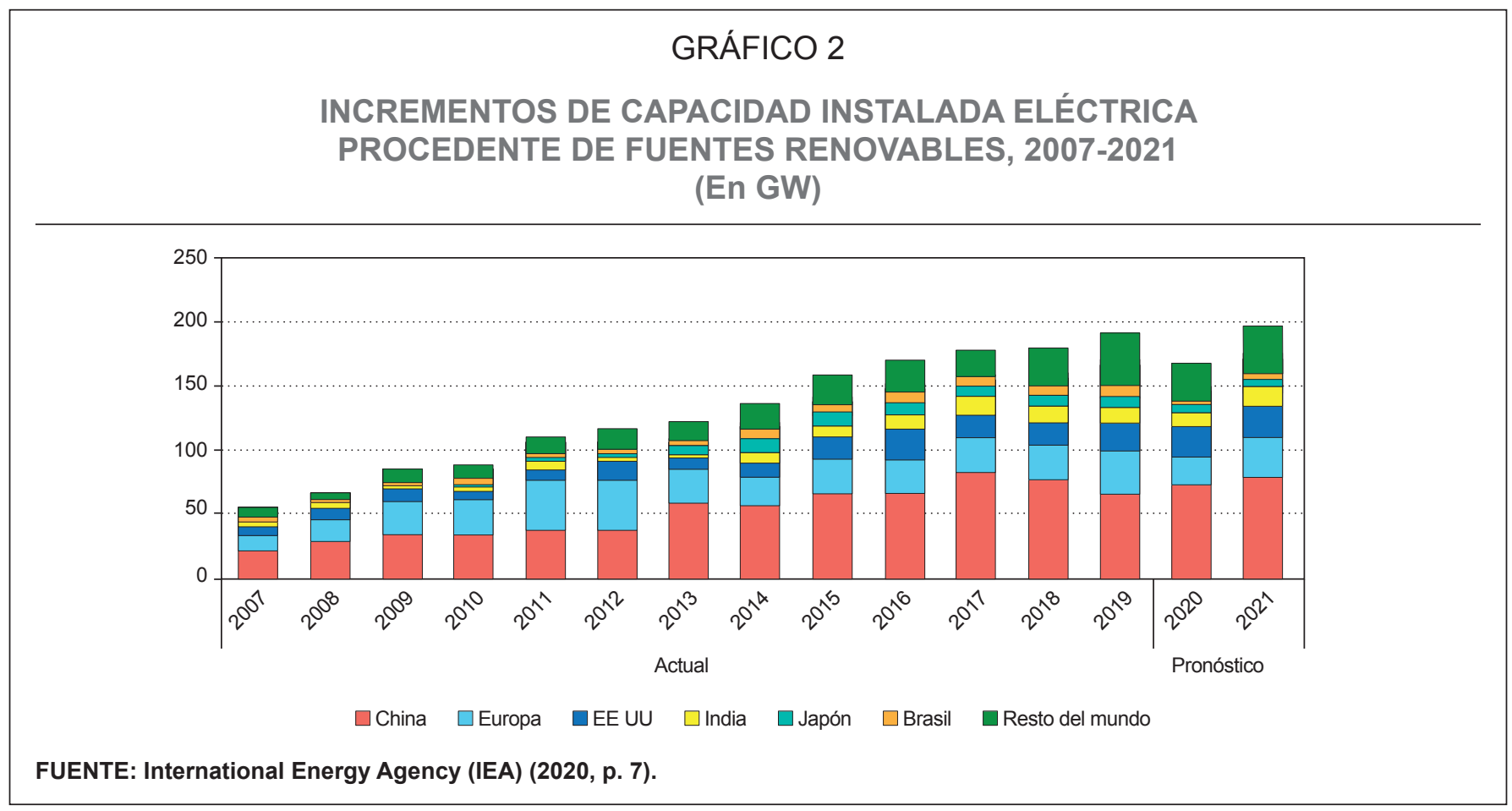

resaltar lo mucho que están contribuyendo a la lucha contra la pandemia del COVID-19 a base de producir productos de plástico (mascarillas desechables, guantes y otros equipos de protección) y medicinas.

Los consumidores también pueden alterar sus preferencias en respuesta a la crisis y priorizar lo económico por encima de lo ambiental, por ejemplo, a base de limitar sus inversiones en eficiencia energética y en vehículos eléctricos, sobre todo si la caída en el $\mathrm{PIB}^{2}$ y el aumento en las tasas de desempleo persisten y/o se vuelven más pronunciados. Algunos ministros de finanzas han expresado sus dudas sobre si un paquete de estímulo verde podría implementarse lo bastante rápido como para ser un instrumento clave de recuperación económica, y no solo una herramienta más (aunque de gran importancia).

\footnotetext{
2 Todavía es pronto para anticipar el impacto de la crisis del coronavirus sobre el crecimiento y el empleo. Según las últimas estimaciones del Gobierno, el PIB de España puede reducirse en un $9,2 \%$ en 2020 (Ministerio de Hacienda, 2020), estimaciones que el FMI fija en $-12,8 \%$ (IMF, 2020), ambas dentro del rango de estimaciones del Banco de España (Banco de España, 2020).
}

Sin embargo, otros ministros de finanzas como Olaf Scholz en Alemania han mostrado su apoyo a los paquetes de estímulo verdes como respuesta a la crisis del COVID-19 (Parkin, Wilkes \& Carr, 2020).

De manera tal vez contraintuitiva, la caída de precios de los combustibles fósiles y unas respuestas de política económica y energética adecuadas a la crisis del coronavirus pueden favorecer la transición energética y a los sectores de la economía verde en su conjunto (Ontiveros, 2020). Sobre todo porque, como muestran las encuestas, la sostenibilidad y los valores ecológicos están cada vez más arraigados en Europa (Comisión Europea, 2019a; Poortinga et al., 2018) y en España (Lázaro, Enríquez \& Escribano, 2019). Esas actitudes ambientales pueden reducir en parte el atractivo que ofrecen unos precios más bajos de los combustibles fósiles para buena parte de los consumidores y limitan el espacio de las políticas energéticas gubernamentales y de las empresas, primando los denominados criterios ESG (Environmental, Social and Governance) (Morrow \& Ma, 2020). De hecho, los análisis de HSBC indican que las acciones de las 


\section{GRÁFICO 3}

\section{APOYO A UNA RECUPERACIÓN «VERDE» POS-COVID-19}

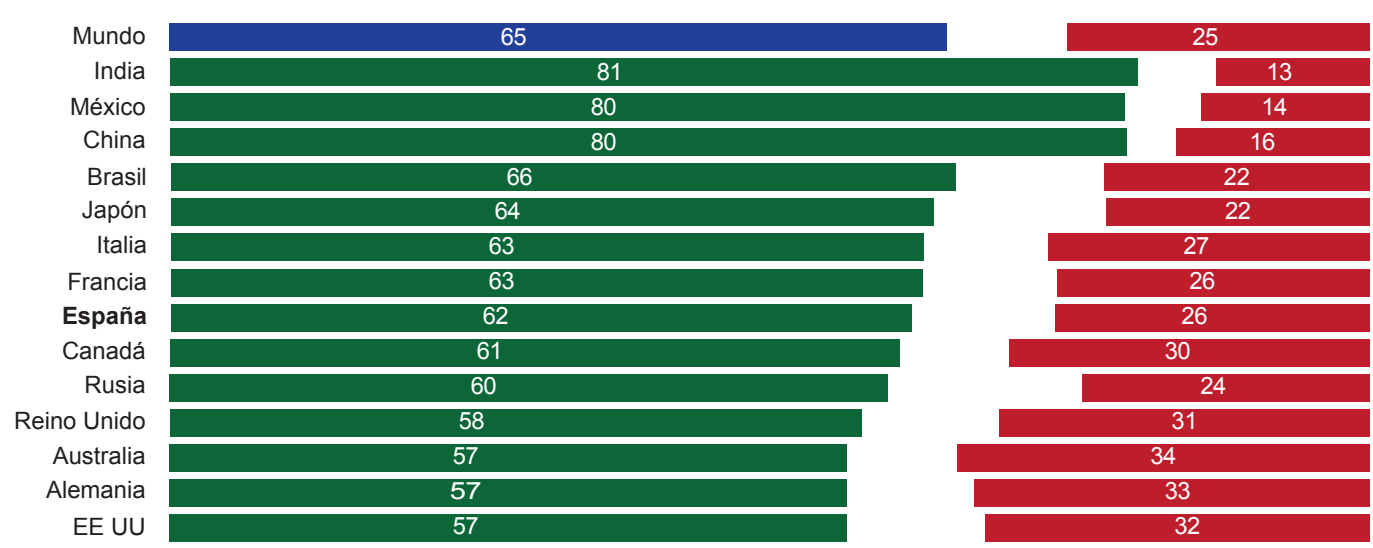

FUENTE: IPSOS (2020a).

empresas que apuestan por criterios ESG han tenido un mejor comportamiento en bolsa durante la primera ola del COVID-19 que aquellas empresas que no apuestan por seguir criterios ESG (Paun, 2020). Asimismo, la mayoría (65 \%) de los ciudadanos a nivel global apoya una recuperación «verde» según una encuesta reciente realizada (Ipsos, 2020a) (Gráfico 3).

Por otro lado, la caída de precios del gas y del petróleo supone una gran oportunidad para eliminar los subsidios o aumentar los impuestos a los combustibles fósiles sin elevar los precios finales. Se evitaría así desatar la ira de los ciudadanos afectados, como ha ocurrido en los últimos meses en Ecuador, Irán, Brasil y Francia, entre otros países. Según la Agencia Internacional de la Energía, los subsidios a los combustibles fósiles han continuado aumentado en los últimos años hasta alcanzar los 400.000 millones de dólares en 2018, y el $40 \%$ de ellos se destinan a abaratar los productos del petróleo, no siempre de la forma más eficiente ni progresiva (Matsumara \& Adam, 2019). Es cierto que, por razones tanto económicas como sociales, los gobiernos querrán pensárselo dos veces antes de elevar impuestos en el corto plazo. Sin embargo, es posible que eliminar los subsidios a los combustibles fósiles de forma gradual sea una forma relativamente sencilla (y aceptable políticamente) de internalizar las externalidades causadas por las emisiones de gases de efecto invernadero.

Además, a diferencia de reducciones en los precios de los combustibles fósiles del pasado, la industria renovable está bien consolidada, ha atraído a inversores grandes y pequeños, y cuenta con el favor del sector financiero. Por el contrario, las inversiones fósiles han perdido atractivo, corren el riesgo de convertirse en activos varados y estarán sometidas a taxonomías ${ }^{3}$ que serán (con toda proba-

\footnotetext{
3 La taxonomía de la UE es una clasificación de actividades que contribuyen de manera positiva a la consecución de objetivos ambientales, incluidos los objetivos climáticos. El objetivo de la taxonomía es ayudar a inversores y empresas a hacer la transición hacia una economía descarbonizada, resiliente y eficiente en el uso de recursos, evitando así los recursos varados (stranded assets). En la actualidad, dicha taxonomía incluye 70 actividades de mitigación y 68 actividades de adaptación al cambio climático. En el futuro se esperan revisiones a la taxonomía y un aumento en la exigencia de los criterios de alineación de las inversiones con la taxonomía (EU Technical Expert Group on Sustainable Finance, 2020).
} 
bilidad) crecientemente restrictivas, lo cual puede limitar el acceso a la financiación de sus actividades más contaminantes. La realidad del mercado energético ha mutado, y ahora la mejor estrategia de inversión ante la bajada de los precios del petróleo y del gas ya no es reducir la exposición a las renovables, sino precisamente aumentarla (Cohan, 2020). Eso es justo lo que están haciendo muchas compañías petroleras europeas en los últimos meses. De hecho, el hundimiento de los precios del petróleo y del gas ha aumentado la percepción de riesgo del sector para los inversores, que pueden preferir la estabilidad que ofrecen unas tecnologías renovables adecuadamente reguladas (Vetter, 2020). El mayor riesgo para las renovables en la era pos-COVID-19 se deriva de las caídas esperadas del PIB, de aumentos en las tasas de desempleo, y de cómo de predecible sea la legislación, y no tanto en el encarecimiento de los precios relativos (Stromsta, 2020).

La especificidad de la crisis del coronavirus debe también ser tenida en cuenta. Está por ver cómo puede evolucionar la pandemia en los próximos meses y hasta qué punto puede cambiar las actitudes y formas de vida de las sociedades afectadas. La generalización del teletrabajo, por ejemplo, puede persistir más allá de la emergencia sanitaria y fomentar nuevos modelos empresariales y de movilidad, tanto domésticos como internacionales (Demertzis et al., 2020). Este es un cambio que, de producirse, ayudaría a reducir las emisiones del sector del transporte, uno de los sectores que más contribuyen a las emisiones de gases de efecto invernadero y que son más difíciles de descarbonizar. Por otro lado, se corre el riesgo de que la crisis del coronavirus afecte negativamente a los modelos de movilidad públicos y colaborativos/compartidos, por lo menos a corto plazo.

Sin embargo, comportamientos tan arraigados como el uso del vehículo privado son complejos de modificar, siendo imprescindible no solo cambios en la planificación urbana, cambios en los usos y costumbres en las empresas y empleados, la disponibilidad de medios de transporte públicos y de bajas emisiones, sino también cambios educativos y culturales que requerirán tiempo
(Cass \& Faulconbridge, 2016). Además, factores como el llamado face-to-face buzz ${ }^{4}$, analizados hace más de tres lustros por Storper y Venables (2004), entre otros, pueden limitar el alcance de las medidas de distanciamiento, una vez pase la crisis.

Lo que sí puede acelerarse, sin embargo, es la electrificación de la movilidad. El petróleo barato supone, en principio, una amenaza para el coche eléctrico; no obstante, sus ventas cada vez tienen más que ver con regulaciones que no van a desaparecer. En Europa, China o California, por ejemplo, se han fijado un máximo de emisiones del parque automovilístico y fechas límite de venta de vehículos con motor de combustión interna (VMCl). Dinamarca, Francia, Alemania, Irlanda, Países Bajos, Noruega, Portugal, Eslovenia, España, Suecia y Reino Unido han dejado clara su intención de prohibir la venta de los $\mathrm{VMCl}$ entre el 2030 y el 2040 (Mileu, 2020), siguiendo las propuestas de la UE. Fuera de Europa, países como Egipto, la India, Israel y Sri Lanka (Coltura, s. f.), entre otros, están considerando propuestas parecidas. China también está considerando prohibir los $\mathrm{VMCl}$ en algunas regiones, una medida que, según el Ministerio de Industria, podría extenderse a todo el país (Reuters, 2019).

Tampoco se va a revertir la caída de precios de las baterías, por lo que una vez que el coche eléctrico alcance la paridad de precios de venta, alrededor de 2023 según estimaciones de Bloomberg New Energy Finance (BNEF, 2019), será más competitivo, independientemente del precio de los combustibles fósiles: el precio de las baterías, no el del petróleo, será entonces el vector determinante (además de la disponibilidad de puntos de recarga para vehículos eléctricos) a la hora de decidir si comprar un vehículo eléctrico. Por otro lado, no parece probable que las enormes inversiones en la electrificación de su

\footnotetext{
4 Se argumenta que el contacto cara a cara es especialmente importante en situaciones en las que la información es imperfecta, e contexto es cambiante y para el desarrollo de actividades creativas ya que el contacto personal aumenta, entre otros, el aprendizaje, la socialización y la motivación (Storper \& Venables, 2004).
} 
oferta realizadas por la industria automovilística vayan a cambiar por las oscilaciones temporales del precio del petróleo. La apuesta de la industria es a largo plazo y la electrificación de la movilidad parece imparable (Millán Lombrana, Shankleman \& Rathi, 2020).

El caso del coche eléctrico muestra la relevancia de las políticas públicas, que no solo deben mantenerse, sino intensificarse, para potenciarlo. La clave del impacto del coronavirus sobre la transición energética está en las políticas para contrarrestar sus efectos económicos y sociales. Es bien conocida la recomendación de Rahm Emanuel, asesor del presidente Obama, sobre la importancia de no desaprovechar una buena crisis. Se refería tanto a las crisis del petróleo de los años setenta como a la Gran Recesión, apuntando que en ambas había que aprovechar la ocasión para impulsar nuevos modelos económicos, en especial energéticos, que no estuviesen basados en el petróleo barato. Asimismo se ha argumentado que la actual crisis ofrece la oportunidad para construir un capitalismo diferente, aprovechando un mayor papel del Estado para condicionar el apoyo público a una reconversión a la economía verde y la descarbonización de los sectores que soliciten dicho apoyo (Mazzucato, 2020).

En el mismo sentido se ha manifestado el director de la Agencia Internacional de la Energía, Fatih Birol, para quien «las energías limpias deben estar en el corazón de los planes de estímulo económico» de los gobiernos. A diferencia de otros posibles estímulos, aquellos dirigidos a las tecnologías energéticas bajas en carbono, a infraestructuras para su integración y a mejorar la eficiencia energética, pueden tener impactos positivos tanto a corto como a largo plazo (Birol, 2020). De hecho, una de las lecciones de la crisis debería ser la importancia de alcanzar un desarrollo sostenible (Tocci, 2020). Pero, además de los estímulos, también pueden instrumentarse otras medidas fiscales: al igual que la caída de los precios del petróleo y del gas permiten reducir los subsidios a los combustibles fósiles, la caída de los precios del $\mathrm{CO}_{2}$ ofrece una oportunidad para gravar las emisiones. Dada la actual situación de limitada movilidad, podría revisarse la fiscalidad también en el sector transporte sin penalizar en exceso a los ciudadanos, si bien será necesario prestar particular atención a los consumidores vulnerables (Plumer \& Fountain, 2020).

\section{La transición pos-COVID-19 en la UE, EE UU y China}

La UE espera salir de la crisis del COVID-19 reforzando su papel de líder direccional. La alineación de valores e intereses en materia de transición energética se refuerza en el contexto pospandemia, si bien la implementación del Pacto Verde Europeo como uno de los ejes fundamentales de la Comisión dependerá en parte del comportamiento del PIB, de las tasas de desempleo y los niveles de déficit y deuda de los Estados miembros. La alta dependencia energética de la UE (que importaba en 2018 un 58,2 \% de su energía bruta, con una alta dependencia de Rusia), los compromisos climáticos crecientemente ambiciosos, una legislación ambiental cada vez más exigente, la existencia de hojas de ruta hacia la neutralidad en carbono (plasmadas, entre otros, en los Planes Nacionales Integrados de Energía y Clima y las estrategias de descarbonización a largo plazo), y la capacidad histórica de desacoplar las emisiones del crecimiento económico, se combinan con tipos de interés históricamente bajos y paquetes de estímulos sin precedentes que brindan la oportunidad de sentar las bases para la transformación del modelo de desarrollo de la UE. No obstante, en concordancia con lo comentado a nivel global, en la UE es de esperar un retraso en la adopción de algunas medidas de política climática y energética al estar los esfuerzos políticos y económicos centrados en la respuesta inmediata a las crisis, sanitaria, social y económica.

En concreto, en el ámbito regulatorio europeo, se esperaba que algunas de las iniciativas del Pacto Verde Europeo pudieran verse retrasadas (Simón, 2020). A mediados de abril la Comisión 
Europea esperaba mantener los tiempos de adopción de la hoja de ruta para la estrategia renovada de finanzas sostenibles, el plan de la Comisión de revisar el objetivo de reducción de las emisiones de la UE para 2030 y su evaluación de impacto. Se esperaban retrasos en otros ámbitos: el establecimiento del Pacto Climático Europeo (European Climate Pact), la revisión de la Directiva sobre la divulgación de información no financiera, la Estrategia «de la Granja a la Mesa» (adoptada a finales de mayo por la Comisión Europea), la Estrategia para una integración sectorial inteligente, la Estrategia para energía renovable offshore, la Estrategia sobre Biodiversidad para 2030 (también adoptada a finales de mayo de 2020), el VIII Programa de Acción en materia de Medio Ambiente, la Estrategia de productos químicos para la sostenibilidad y la Estrategia para una movilidad sostenible e inteligente. Se esperaban también retrasos en la Estrategia de adaptación al cambio climático, la Estrategia forestal de la UE revisada, el empoderamiento de los consumidores para la transición verde, ReFuelEU Aviation -combustibles de aviación sostenibles- y FuelEU Maritime un Espacio Marítimo Verde Europeo. En algunos Estados miembros tales como Alemania, la crisis del coronavirus ya ha generado un retraso de las decisiones relacionadas con el despliegue de energías renovables necesario para cumplir sus compromisos (Manuell, 2020), si bien se espera que el plan de recuperación alemán asigne alrededor de un tercio del paquete de estímulo total de 130.000 millones de euros a una salida «verde y resiliente al futuro».

La negociación de la respuesta económica a corto y medio plazo a la crisis del COVID-19 por parte de la UE está aún por concluir. No obstante, es de esperar que tanto el próximo presupuesto de la UE (el Marco Financiero Plurianual 2021-2027, MFF, por sus siglas en inglés) de 1,1 billones de euros, como el nuevo instrumento temporal de recuperación (Next Generation EU), dotado con 750.000 millones de euros, sean más verdes que sus homólogos poscrisis financiera de 2008. Así, se espera que del total del MFF y del instrumento Next Generation EU se destine un $30 \%$ a proyectos con impacto positivo para el clima, encaminados a conseguir la neutralidad climática en 2050, estén alineados con el Acuerdo de París y se guíen por los objetivos marcados en el Semestre Europeo y por los pilares del Pacto Verde Europeo - digitalización y transición hipocarbónica(European Council, 2020). Además, la recientemente publicada taxonomía, un «diccionario» de aquellas actividades con impacto positivo en el cambio climático, podría servir de guía para unos paquetes de estímulos inéditos, en pro de la alineación de los flujos financieros con los objetivos climáticos, como establece el artículo 2.1.c. del Acuerdo de París.

De hecho, el Pacto Verde Europeo proporciona una guía para los estímulos económicos alineada con los intereses y los valores europeos. Algunos Estados miembros se precipitaron a exigir a la Comisión Europea que abandonara el Pacto Verde y se concentrara en combatir el coronavirus (Euractiv, 2020), sin darse cuenta de que precisamente dicho pacto puede ser uno de los mecanismos más efectivos, a corto y medio plazo, para contrarrestar los efectos económicos de la pandemia. Los Estados miembros opuestos al Pacto Verde no deberían poder conseguir su paralización con el argumento de centrarse únicamente en la respuesta al coronavirus. En cambio, los países mediterráneos de la UE, que se encuentran entre los más afectados en términos sanitarios y económicos, pueden beneficiarse de manera significativa de una aceleración de la transición energética, lo que a su vez redundaría en una mayor contribución por su parte a alcanzar la neutralidad climática europea en 2050.

Así, lejos de constituir una rémora para la transición energética y un revés para el Pacto Verde Europeo, la crisis del coronavirus ofrece una oportunidad para profundizar en ambos. Los efectos positivos del Pacto Verde Europeo no solo se notarán a corto plazo, sino también en el futuro. Si hay Estados miembros en la UE que no quieren avanzar en la descarbonización y 
no creen en esta estrategia de recuperación económica, basta con que renuncien a los estímulos europeos adoptados en la lucha contra el COVID-19 y que pueden canalizarse a través del Pacto Verde Europeo.

En EE UU, como cabía esperar, la Administración Trump ha reaccionado en sentido diametralmente opuesto a la UE. Ha activado las políticas para rescatar al fracking y ha relajado las normas medioambientales a base de permitir que sean las propias compañías las que decidan si se ven capaces de cumplirlas en el contexto actual (Friedman, 2020). EE UU también ha relajado los objetivos de emisiones para los vehículos y las medidas para mejorar la eficiencia en el uso de combustibles. Trump ha relajado además las medidas para limitar las emisiones procedentes de la producción de energía eléctrica y los estándares relativos a contaminación del aire por partículas finas. Esto solo creará un mayor daño medioambiental con el que habrá que lidiar una vez finalizada la crisis del COVID-19. Sin embargo la elección de un presidente demócrata en noviembre de 2020 podría suponer que EE UU revierta las medidas de la Administración Trump, apueste por la transición energética y plantee limitaciones al fracking.

China es otro foco de preocupación, si la senda escogida para su recuperación económica consiste en aprovechar los bajos precios de gas y petróleo para impulsar sectores intensivos en hidrocarburos y emisiones (Meidan, 2020). Las señales provenientes de China relativas al tipo de salida de la crisis del COVID-19 son, por el momento, ambiguas. Históricamente China ha antepuesto el crecimiento económico a la protección ambiental, si bien es cierto que a partir de su XI Plan Quinquenal, el medioambiente, la transición hacia una economía de menores emisiones y la apuesta por las energías renovables ha ido ocupando un espacio cada vez mayor en las políticas públicas en materia energética. Es más, en la última década China ha sido el mayor inversor a nivel global en energías renovables, 758.000 millones de euros entre 2010 y mediados de 2019 (Frankfurt School-UNEP, 2019), aunque su proyecto de la Franja y la Ruta está todavía lejos de alinearse con los objetivos climáticos planteados en el Acuerdo de París (Esteban \& Lázaro, 2020).

Si bien China ha abandonado su objetivo de crecimiento económico para 2020 por primera vez en décadas, y ha anunciado que apostará por la modernización de su sector automovilístico, el $5 \mathrm{G}$ y las manufacturas «inteligentes», se podría esperar que las presiones regionales y de la industria intensiva en el uso de energía limiten una salida a la crisis del COVID-19 completamente alineada con los objetivos del Acuerdo de París.

De hecho, la industria automovilística china ya ha pedido flexibilidad en las normativas de emisiones. Además, el Gobierno chino está eliminando restricciones a la compra de coches, recortando impuestos a los coches pequeños e implementando otras medidas de apoyo a los vendedores de coches. Cabe añadir que el miedo al contagio en transporte público puede incrementar la demanda para el uso individual de coches, como se ha observado en China, donde ha subido la venta de coches pequeños (Ipsos, 2020b). Por otro lado, las autoridades chinas también han establecido subsidios para la compra de vehículos eléctricos para prevenir el aumento del $\mathrm{CO}_{2}$ y de otras partículas a medio plazo, y van a reintroducir los subsidios para los híbridos enchufables y los vehículos de pila de combustible hasta que estos puedan competir libremente con los vehículos de combustión interna.

\section{Desde España para Europa: propuestas para una recuperación verde}

En los próximos meses se adoptará el Marco Financiero Plurianual 2021-2027 de la UE, tras el acuerdo político del Consejo Europeo de julio de 2020, en el que se incluía también un instrumento temporal (2021-2024) de recuperación específico tras la crisis del coronavirus (Next Generation EU, NGEU) que asciende conjuntamente a 1,82 billones de euros (Consejo Europeo, 2020). En el nuevo marco Marco Financiero Plurianual se espera un papel importante para las estrategias de recuperación verde y el reforzamiento del 
Pacto Verde Europeo. España es uno de los países que ha demandado esa dimensión verde de las propuestas de recuperación desde un contexto difícil por la situación sanitaria, social y económica del país, pero más favorable desde la perspectiva de la política energética y climática española.

Los objetivos de España en materia de descarbonización son de los más ambiciosos de la UE (Comisión Europea, 2019b) si se tiene en cuenta el esfuerzo que debe hacer España desde 2017 hasta 2030. Los motivos de esta ambición se sustentan en los impactos esperados del cambio climático, ya que España es un «punto caliente» en lo que al cambio climático se refiere. En este sentido se esperan aumentos de los fenómenos meteorológicos extremos e impactos significativos en sectores como el turismo o la agricultura. Por otro lado, España cuenta con buen recurso renovable (por ejemplo, solar y eólico) y nuestra industria renovable sigue estando entre las primeras a nivel mundial. Por último, nuestra gran dependencia energética ( $74 \%$ frente al $58,2 \%$ de media de la UE) supone pagos elevados por combustibles fósiles importados (MITECO, 2020). Así, tanto los impactos del cambio climático como nuestros recursos, capacidades y dependencia energética apoyan una propuesta de descarbonización ambiciosa y justa.

La ambición de España en materia climática se refleja en el Plan Nacional Integrado de Energía y Clima (PNIEC) 2021-2030, el documento de base que debe guiar las decisiones de inversión para la transformación del modelo económico de España hasta 2030. Su objetivo es avanzar en la descarbonización y para ello hace especial énfasis en el ámbito energético, ya que es el sector que genera tres cuartas partes de las emisiones. La inversión requerida por el PNIEC es de 241.412 millones de euros desde 2021 hasta 2030, el $80 \%$ de la cual provendría del sector privado. Algunas de las medidas clave del plan son:

- La transformación del sector eléctrico para que en 2030 el $74 \%$ de la electricidad y el $42 \%$ de la energía final provenga de fuentes renovables. El objetivo es alcanzar $161 \mathrm{GW}$ de potencia renovable instalada en 2030: 50GW de energía eólica, 39GW de solar fotovoltaica, $16 \mathrm{GW}$ de hidráulica, 9,5GW de bombeo y $7 \mathrm{GW}$ de solar termoeléctrica, si bien el PNIEC indica que la distribución por tecnologías dependerá de los costes relativos, entre otros factores.

- La renovación de edificios (envolvente térmica de 1,2 millones de edificios hasta 2030 y calefacción y Agua Caliente Sanitaria (ACS) de 300.000 edificios al año hasta 2030), aunque hay problemas por solventar, pues nunca hemos sido capaces de llevar a cabo una renovación a semejante escala y hay que buscar fórmulas aceptables para financiarla.

- Respecto al transporte, el objetivo es alcanzar 5 millones de vehículos eléctricos en 2030. Aunque, como ya hemos mencionado, se espera que el coche eléctrico alcance la paridad de precios de venta entre 2023 y 2024, estas cifras pueden resultar optimistas y hay que contar con la aprobación de la Ley de Cambio Climático y Transición Energética para poner en marcha la red de recarga en todo el territorio.

En este doble contexto español de dificultades económicas y claras oportunidades de salida verde de la crisis, cabe plantearse qué tipo de propuestas podría aportar España para contribuir simultáneamente a su recuperación económica y al Pacto Verde Europeo. Según un análisis recientemente publicado por Hepburn et al. (2020), en el que se analizan 700 políticas de estímulo propuestas o adoptadas desde 2008 y se presentan los resultados de una encuesta a 231 expertos que trabajan en bancos centrales y ministerios de finanzas, se destaca que entre las medidas que generan un mayor impacto positivo para el clima y mayor efecto multiplicador a largo plazo se incluyen: la inversión en energías renovables y en infraestructuras limpias, la inversión en I+D (en general y enfocada a la descarbonización) y la inversión en educación (Hepburn et al., 2020).

Además, como indicábamos, la opinión pública española es claramente favorable a apoyar una salida «verde» a la crisis del COVID-19, lo cual se sustenta en una creciente preocupación por el cambio climático. 


\section{GRÁFICO 4}

\section{PREFERENCIAS PARA EL PRESUPUESTO EUROPEO. ÁREAS EN LAS QUE LA UE DEBE INVERTIR MÁS (En \% personas que quieren aumentar el gasto)}

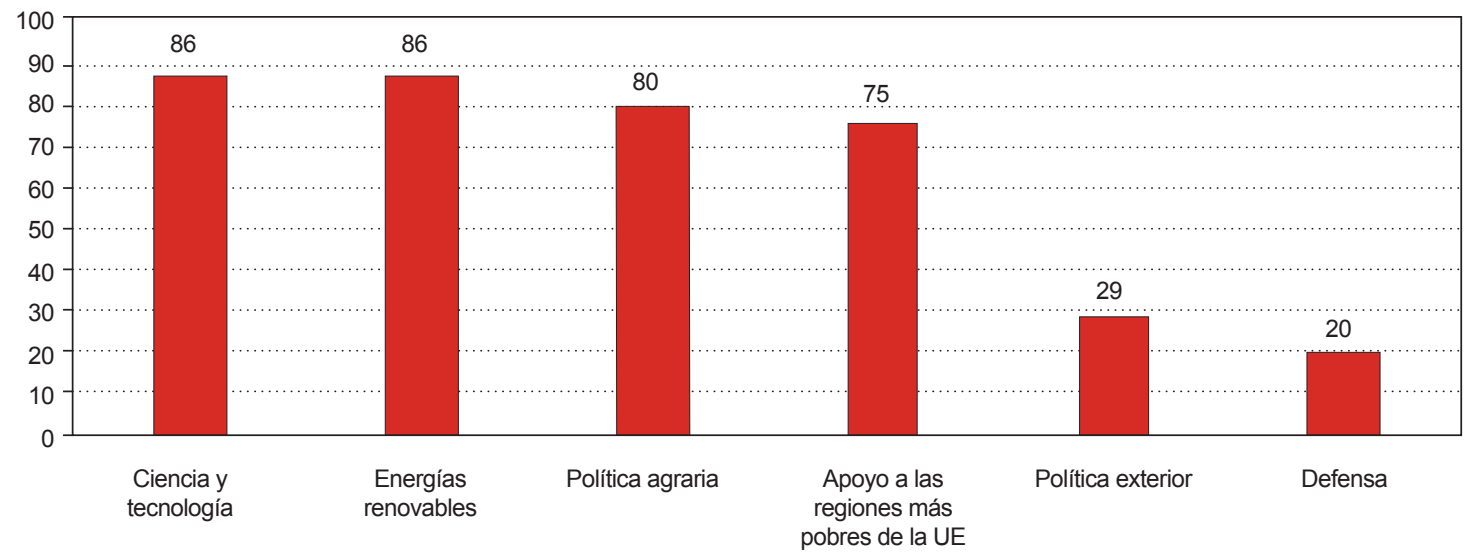

NOTA: $\mathrm{N}=1.000$.

FUENTE: Real Instituto Elcano (2020, p. 18).

Según el último Barómetro del Real Instituto Elcano, la lucha contra el cambio climático es la primera prioridad en materia de política exterior para los españoles, la mayoría de los cuales piensa que estamos ante una emergencia climática $(61 \%)$ o en una situación grave en relación con el cambio climático (31\%) (Real Instituto Elcano, 2020). Así, cuando se pregunta a los españoles por las partidas presupuestarias que deben incrementarse en el próximo presupuesto europeo 2021-2027, los españoles revelan su prioridad por invertir más en ciencia y tecnología, y en energías renovables, seguidas por la política agraria y el apoyo a las regiones menos desarrolladas de la UE (Gráfico 4).

En paralelo, una parte significativa de la comunidad empresarial, a través del Grupo Español de Crecimiento Verde, que representa casi la mitad del IBEX 35, apoya firmemente una estrategia de salida verde a la crisis del COVID-19 en una declaración publicada recientemente (Grupo Español para el Crecimiento Verde, 2020). Los partidos políticos, por su parte, con la única excepción de VOX, tienden a estar razonablemente alineados (para los estándares políticos españoles) respecto a la necesidad de promover una salida verde a la crisis del coronavirus. Al igual que los partidos de coalición del Gobierno, Partido Popular y Ciudadanos firmaron la Alianza Europea para la Recuperación Verde promovida por Pascal Canfin, presidente de la Comisión de Medio Ambiente del Parlamento Europeo (Green Recovery Alliance, 2020).

En consecuencia, parece oportuno que España plantee propuestas ambiciosas de recuperación verde para Europa, que incluirían los siguientes elementos:

- Primero, sería necesario contar con nuevos análisis que permitan priorizar las inversiones propuestas en el PNIEC, que actualicen los datos económicos pos-COVID-19 y utilizando dicho plan como una herramienta clave de la recuperación económica alineada con nuestros compromisos climáticos. Sería necesario establecer un diálogo con el sector privado para determinar si ese $80 \%$ de inversión proveniente del sector 


\section{GRÁFICO 5}

\section{APOYO CIUDADANO A LAS RESTRICCIONES AL TRÁFICO EN EL CENTRO DE LAS CIUDADES, ESCALA 0-10}

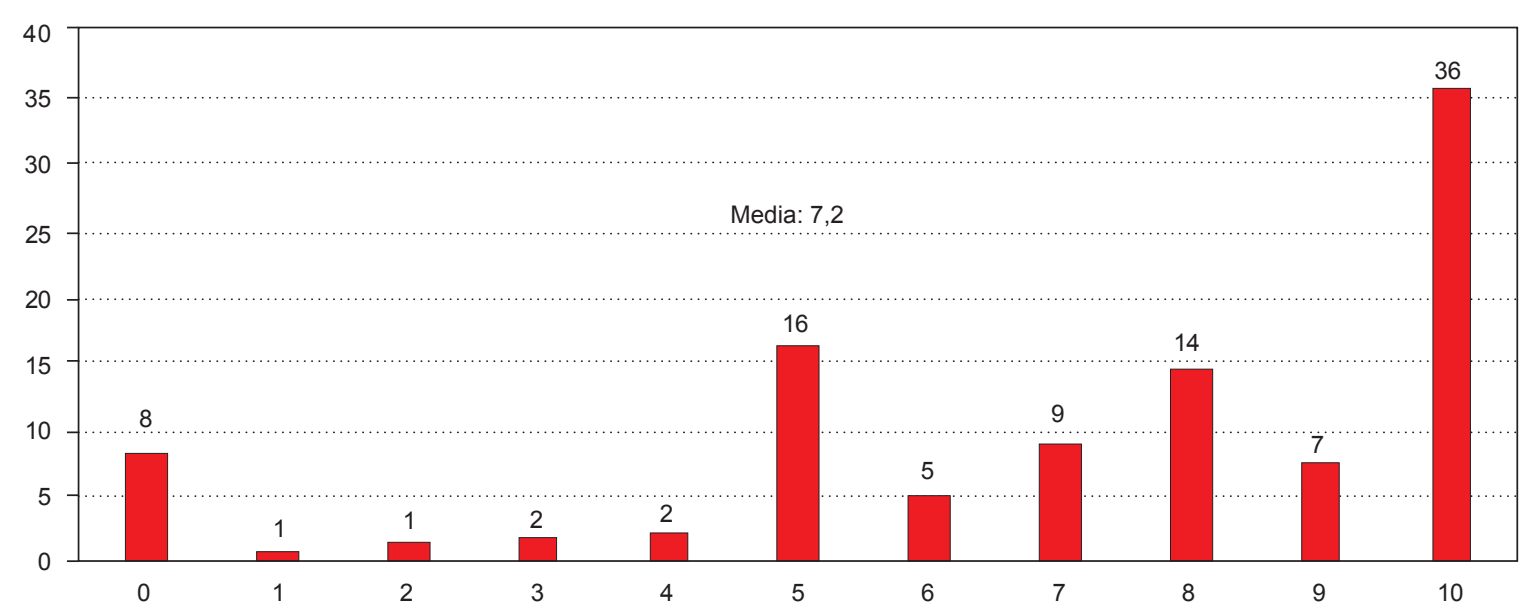

FUENTE: Real Instituto Elcano (2020, p. 26).

privado contemplado en el PNIEC sigue siendo factible en el nuevo contexto de la crisis del COVID-19, o si incluso pudiera aumentarse por parte de algunos sectores y empresas. También sería importante proporcionar un marco regulatorio adecuado para el despliegue de las renovables, incluyendo las subastas para las diferentes tecnologías (Mora et al., 2017).

- Segundo, debe asegurarse una salida verde a la crisis de suerte que las inversiones se centren en aquellos sectores con mayor potencial de creación de empleo a corto plazo, con mayor impacto en la reducción de emisiones y con mayor efecto multiplicador a largo plazo. En este sentido, el Grupo de Expertos Técnicos en Finanzas Sostenibles (TEG) de la Comisión Europea ha desarrollado tres herramientas entre 2018 y 2020 con el fin de ayudar a guiar las inversiones tanto de gobiernos como del sector privado, y que pueden servir de guía en la salida del COVID-19 (Ecopost, 2020): la Taxonomía Sostenible (EU Technical Expert Group on Sustainable Finance, 2020), el estándar de Bonos Verdes (Comisión Europea, 2019c) y los índices de referencia de Transición
Climática y Alineados con París (EU Technical Expert Group on Sustainable Finance, 2019). Según la literatura académica (Hepburn et al., 2020) y nuestro PNIEC, esto supondría apostar por invertir en el despliegue de renovables, con la priorización que indiquen los nuevos análisis del PNIEC, si los hubiere. También supondría implementar los objetivos de mejora de la eficiencia energética en edificios, impulsando el sector de la construcción sostenible.

- Tercero, debería trabajarse para consolidar la electrificación del transporte en el nuevo contexto. También debe apostarse por establecer zonas de bajas emisiones en las ciudades que mejoren la calidad del aire, que aporta importantes beneficios colaterales para la salud de los ciudadanos, además de contribuir a reducir las emisiones de gases de efecto invernadero (medida que cuenta además con un fuerte apoyo ciudadano, como se observa en el Gráfico 5). Ello requeriría nuevas medidas de movilidad sostenible, incluyendo mejores infraestructuras de transporte público, el fomento de nuevos modelos de movilidad urbana, el despliegue 
de flotas sostenibles para el vehículo compartido, la peatonalización y más carriles bici.

- Cuarto, deberían establecerse criterios claros relativos a la condicionalidad de las ayudas que eventualmente puedan recibir los sectores y empresas intensivos en emisiones: transporte pesado, aviación, refino, química, acero, fertilizantes, cemento y cal, cerámica, papel, vidrio y metales no ferrosos, entre otros. Estos sectores deberían presentar planes de descarbonización con el objetivo de alcanzar la neutralidad en carbono en 2050. Deberían además indicar objetivos intermedios de descarbonización a 2030 y 2040 . El progreso en la consecución de estos objetivos debería ser evaluado periódicamente. Si los objetivos de descarbonización no se cumplieran se podría plantear que los gobiernos recuperasen la financiación vía participaciones en las empresas (Hepburn et al., 2020).

- Finalmente, los resultados del proyecto H2020 MUSTEC (Market Uptake of Solar Termal Electricity through Cooperation), en el que participa el Real Instituto Elcano, indica que España se convertiría en el mayor exportador de electricidad de origen renovable de la UE, si se cumplen todos planes de descarbonización de manera cooperativa entre Estados miembros. Para poder exportar esa electricidad, según las modelizaciones preliminares manejadas en el proyecto, necesitamos aumentar nuestra capacidad de interconexión hasta cerca de $25 \mathrm{GW}$ en 2030 y a $40 \mathrm{GW}$ a mediados de siglo. Esto supone multiplicar varias veces nuestra capacidad de interconexión actual con Francia. Sería necesario contar con la financiación suficiente para asegurar estas interconexiones si España aspira a exportar electricidad renovable en base a sus ventajas comparativas naturales y empresariales (estáticas y dinámicas), y contribuir así a la recuperación económica de la UE y a cumplir con sus objetivos de energía y clima.

\section{Gobernanza climática}

Retomando la reflexión inicial sobre las previsiones para 2020 en materia de clima (Lázaro, 2020), es preciso resaltar que con la pandemia de COVID-19 se acentúan las dificultades en el proceso de gobernanza climática global y se hace más necesario que nunca, si cabe, escuchar a la ciencia. Tanto la pandemia causada por el coronavirus como la emergencia climática son crónicas de crisis anunciadas, y los paralelismos se han resaltado en círculos académicos. Si bien ambas tienen plazos de «incubación» muy distintos, días o semanas en el caso del coronavirus y siglos en el caso del cambio climático, ambas crisis ilustran el problema del crecimiento (de los contagios y de las emisiones) frente a unos medios (sanitarios o planetarios) limitados (Gardiner, 2020). Además, su resolución pasa inexorablemente por seguir las recomendaciones científicas, a las que estamos haciendo caso tarde en el caso del coronavirus y que hemos ignorado en gran medida respecto al cambio climático.

Cheng et al. (2007) indicaban que los hábitos de consumo de especies exóticas eran una «bomba de relojería» que podía provocar una pandemia y que debíamos estar preparados. En 2020, el análisis de riesgos del Foro Económico Mundial situaba las enfermedades infecciosas como el décimo riesgo a nivel global en términos de impacto, subrayando que ningún país del mundo estaba bien preparado para enfrentarse a una pandemia como la que estamos sufriendo (WEF, 2020). Parece claro que la ventana de la prevención del COVID-19 se cerró y que la respuesta, que debiera ser global y simultánea, se está forjando en un momento de individualismo diacrónico.

La ciencia del clima, por su parte, lleva informando sobre las causas, las consecuencias y las políticas para limitar los peores impactos del cambio climático al menos desde que en 1988 se creara el Panel Intergubernamental de Expertos sobre el Cambio Climático (IPCC, por sus siglas en inglés). Sabemos, gracias al quinto informe del IPCC, que el cambio climático está ocurriendo, que hay un componente antropogénico claro y que tanto los ecosistemas como nuestras sociedades están sufriendo los impactos del cambio del clima. Sabemos, además, que la actual acción global 
para frenar el cambio climático es claramente insuficiente para evitar sus impactos más severos.

El último informe científico presentado por varias organizaciones bajo el paraguas de la Organización de las Naciones Unidas, Unidos en la Ciencia 2020 (WMO, 2020a), nos recuerda que las concentraciones de gases de efecto invernadero continúan en ascenso, alcanzando su nivel más alto desde hace 3 millones de años. Petteri Taalas, secretario general de la Organización Meteorológica Mundial, indicaba que el periodo 2016-2020 será, previsiblemente, el más cálido desde que existen registros. Taalas subrayaba también que si bien muchos aspectos de nuestra vida se han visto alterados por la pandemia, el cambio climático continúa, en esencia, inalterado (WMO, 2020b). Las emisiones y sus impactos siguen aumentando mientras ignoramos las advertencias de la ciencia.

En relación con el impacto del coronavirus en el cambio climático y en la contaminación del aire, la revista Nature publicaba un artículo en el que se indicaba que las medidas para parar la pandemia han reducido temporalmente las emisiones de gases de efecto invernadero y la contaminación del aire (Callaway et al., 2020), que debilita el sistema respiratorio que ataca el coronavirus (Wu et al., 2020). No obstante, la reanudación de la actividad productiva, y la potencial vuelta a los patrones de consumo precoronavirus, limitarán previsiblemente este respiro temporal al clima.

Respecto a los efectos de la pandemia del COVID-19 y de las medidas de distanciamiento social sobre las respuestas al cambio climático, destacan los siguientes:

1) El impacto sobre el proceso de negociaciones climáticas, con el aplazamiento de la COP 26 de Glasgow y de la cumbre de biodiversidad (COP 15) de Kunming, China.

2) El impacto en el desarrollo de las herramientas de implementación del Acuerdo de París, es decir, en la legislación climática.

En el análisis sobre lo que podía esperarse de 2020, en el ámbito climático se destacaba que este sería un año para el compromiso y la ambición (Lázaro, 2020). La labor de la diplomacia climática y el impulso político resultarían clave a la hora de acortar distancias entre compromisos y objetivos climáticos. Las Contribuciones Determinadas a Nivel Nacional (Nationally Determined Contributions, NDCs) debían ser más ambiciosas que las presentadas en 2015 y las estrategias a largo plazo que nos comprometimos a presentar en $\mathbf{2 0 2 0}$ debían conducirnos hacia la neutralidad climática, lo cual requeriría un capital político y una ambición sin precedentes.

Sin embargo, como no podía ser de otra manera, la pandemia causada por el coronavirus continúa acaparando la atención de los gobiernos. En Italia, que está al frente de la pre-COP 26, la situación fue dramática durante la primera ola del coronavirus, monopolizando la agenda política en el primer semestre de 2020. En el Reino Unido, que ostenta la presidencia de la COP 26, la organización de las acciones y de la agenda para la cita climática más importante desde París comenzaron con retraso (Harvey, 2020).

Así, la mayoría de los líderes políticos y negociadores climáticos acogieron el aplazamiento de la COP 26 con satisfacción, con la esperanza de que el año extra hasta la celebración de la próxima COP en noviembre de 2021 ayude a generar el capital político necesario para elevar la ambición climática. Además de consideraciones sanitarias, una de las razones por las cuales se recibió la noticia del aplazamiento de la COP 26 de manera positiva es que las restricciones a los viajes internacionales limitan necesariamente la labor de la diplomacia climática. Aunque parte de esta labor diplomática se esté llevando a cabo a distancia, la presión de las distancias cortas que permiten las citas presenciales se diluye en los encuentros telemáticos.

Por otro lado, la retirada de EE UU del Acuerdo de París anunciada por Trump proporciona una oportunidad singular a China, posiblemente en tándem con la UE, para hacerse con un liderazgo climático que se encuentra fragmentado. La pandemia del 
COVID-19 limitó el apetito chino de liderazgo durante la primera mitad de 2020 debido al impacto económico del coronavirus, que se espera alcance una tasa de crecimiento del PIB en 2020 que, aun siendo positiva —en el entorno del $1 \%$ según el IMF (2020)—, quedará lejos del objetivo del 6,5\% incluido en su XIII Plan Quinquenal. Además, el aplazamiento de la COP 15 sobre biodiversidad que se iba a celebrar en China, así como de las reuniones preparatorias correspondientes (Convención sobre la Diversidad Biológica, 2020), y de la COP 26 podría retrasar la toma de decisiones que actualmente son más urgentes que nunca (Pickard et al., 2020). También se aplazó la cumbre China-UE de Leipzig, en la cual se esperaba escenificar un compromiso climático ambicioso por ambas partes de cara a la COP 26.

En el contexto actual, si la UE quiere influir en el aumento de la ambición en la segunda ronda de NDCs, tendrá que apoyar diplomáticamente las negociaciones sobre biodiversidad, en un momento en el que las preocupaciones sobre el crecimiento económico dominan la narrativa sobre cómo salir del COVID-19, incluso a costa de no dar respuesta a la emergencia climática.

Para diseñar una respuesta eficaz y socialmente aceptable, los responsables políticos tendrán que incluir los vínculos entre la acción medioambiental (clima y biodiversidad) y la sanidad, subrayando los coimpactos de ambas en sus estrategias de negociación. Esta respuesta también requerirá la inclusión del impacto social de la acción medioambiental, a través de Estrategias de Transición Justa. Los instrumentos financieros verdes también serán clave a la hora de conseguir un equilibrio entre una respuesta a corto plazo a la crisis y la recuperación económica y transformación del modelo económico a medio y largo plazo a las cuales se comprometió la comunidad internacional en el Acuerdo de París.

La UE, por su parte, ya ha enviado a la Secretaría de la Convención Marco de las Naciones Unidas sobre el Cambio Climático (CMNUCC) la comunicación sobre su estrategia de descarbonización a largo plazo.
Según esta, la UE se compromete a alcanzar la neutralidad climática a mediados de siglo en cumplimiento de los compromisos del Acuerdo de París (Presidencia Croata del Consejo Europeo, 2020). Además, se está tramitando la llamada Ley climática europea (Comisión Europea, 2020) como elemento esencial del Pacto Verde Europeo ${ }^{5}$ y se espera que el segundo NDC de la UE incluya un compromiso de reducción de emisiones del $55 \%$ en 2030 con respecto a los niveles de emisiones de 1990, si el Parlamento Europeo y los Estados apoyan el objetivo presentado por Ursula von der Leyen en septiembre.

Al menos sobre el papel, las acciones de la UE parecen estar alineadas con sus compromisos climáticos. Sin embargo, hay dos temas que Europa tiene que abordar si de veras quiere tener un impacto significativo en el devenir climático global:

1) Animar a China a que eleve el nivel de ambición de su Contribución Determinada a Nivel Nacional (NDC). Esto podría hacerse mediante un mayor apoyo diplomático a su agenda de biodiversidad, a la vez que se limita cualquier discusión a corto plazo sobre un impuesto al $\mathrm{CO}_{2}$ en frontera (Ministerio de Ecología y de Medio Ambiente de la República Popular China, 2019). También se debería proponer la creación de grupos de trabajo conjuntos pos-COVID-19 para analizar posibles respuestas coordinadas que incluyan paquetes de estímulo verdes. El anuncio reciente de China en la Asamblea General de Naciones Unidas relativo a su compromiso de alcanzar la neutralidad en carbono en 2060 y adelantar el pico (máximo) en sus emisiones antes de 2030 es una señal esperanzadora en este sentido 6 . No obstante, será necesario estar atentos a cómo se materializan estos anuncios en el próximo NDC chino y en su XIV Plan Quinquenal. Queda además pendiente el análisis y la implementación de medidas para «reverdecer» la Franja y la Ruta

\footnotetext{
5 Debería tenerse en cuenta que en el momento de redacción del presente artículo la llamada Ley climática europea se encuentra en periodo de enmiendas.

6 Véase Mars y Planelles (2020).
} 
(la gran estrategia de conectividad china) a través de la alineación de los flujos financieros con los objetivos climáticos (Esteban \& Lázaro, 2020).

2) Acertar en el diseño de los mecanismos de implementación del Acuerdo de París, es decir, construir un marco legislativo climático que sea robusto. Este proceso tiene que incorporar el conocimiento científico como guía para la toma de decisiones. A pesar de la insistencia por parte de la Comisión relativa a su independencia al proponer legislación basándose en la ciencia, su propuesta inicial para la llamada Ley climática europea adolecía de uno de los elementos clave de la arquitectura institucional para asegurar una regulación climática robusta: no incluía un comité científico independiente que proponga objetivos de reducción de emisiones de manera regular, que presente sus resultados al Parlamento y al Consejo, que evalúe el progreso logrado y exija responsabilidades a los gobiernos. No obstante, tras el voto del comité de Medio Ambiente del Parlamento Europeo de septiembre de 2020, se ha planteado la creación del mencionado comité científico independiente sobre cambio climático, propuesta que podría incluirse en la redacción final de la llamada Ley climática europea previsiblemente en diciembre de 2020 (Schulz, 2020).

En España, la declaración del estado de alarma también centró la atención y la acción del Gobierno durante la primera ola del COVID-19, como era de esperar. Aunque las iniciativas legislativas continuaron en el primer periodo de confinamiento, se retrasó la tramitación parlamentaria de la Ley de Cambio Climático y Transición Energética ${ }^{7}$, así como la presentación de la Estrategia a Largo Plazo para una Economía Española Moderna, Competitiva y Climáticamente Neutra en 2050.

En concordancia con lo ya apuntado para el caso europeo, es necesario reiterar la necesidad de dotar

\footnotetext{
7 Además de haberse presentado una enmienda a la totalidad al proyecto de Ley de Cambio Climático y Transición Energética por parte de VOX que dilata aún más la tramitación parlamentaria.
}

a España de un comité científico independiente. Siguiendo las mejores prácticas, por ejemplo, del Reino Unido, dicho comité propondría objetivos intermedios de reducción de emisiones entre 2030 y 2050 , evaluaría la consecución de los objetivos de mitigación, adaptación y financiación, y asistiría a las comunidades autónomas en el desarrollo y evaluación de sus planes de acción frente al cambio climático. Dicho comité científico podría mejorar el proceso de toma de decisiones del gobierno actual (y de los gobiernos futuros), requiriendo respuestas motivadas a los informes de evaluación, proporcionando consistencia a las políticas gubernamentales, ayudando a avanzar en la Integración de la Política Ambiental (Environmental Policy Integration, $E P I)$ o mainstreaming. Todo ello ayudaría a mejorar la transparencia y la legitimidad de las decisiones, contribuyendo a elevar el debate público y respondiendo a la emergencia climática desde el conocimiento revisado por pares (Fankhauser et al., 2018).

\section{Conclusiones}

Aunque resulta complicado elaborar conclusiones y recomendaciones claras en el período de incertidumbre radical en que nos encontramos, podrían plantearse las siguientes.

Estamos en una encrucijada política en la cual tenemos que decidir si queremos pensar estratégicamente y adoptar paquetes de estímulo verdes que puedan ayudarnos a maximizar la sexta ola de innovación (Silva \& Di Serios, 2016), en concordancia con nuestros compromisos energéticos y climáticos a medio y largo plazo, o si queremos centrarnos exclusivamente en respuestas cortoplacistas, asumiendo así que nuestro modelo económico actual es el mejor para el futuro. Si se pueden replicar experiencias pasadas a la hora de aplicar planes de estímulo verde (por ejemplo, el caso de Corea del Sur después del 2008), y si queremos responder de forma eficaz a la emergencia climática a la vez que al COVID-19, los planes de estímulo verdes que existen globalmente, y 
el Pacto Verde Europeo, nos ofrecerían una oportunidad única para aplicar objetivos y medidas como los incluidos en los NDCs a nivel global y en los PNIECs y las estrategias de descarbonización a largo plazo a nivel europeo, cuya rápida implementación también podría fomentar que los flujos financieros internacionales se alineasen con los objetivos de los Acuerdos de París.

En relación con el impacto de la pandemia del COVID-19 sobre la transición energética y el Pacto Verde Europeo, se concluye que, lejos de constituir un revés, ofrece una oportunidad para intensificar los esfuerzos de descarbonización. Una de las medidas de estímulo económico más claras que se puedan adoptar hoy en Europa es acelerar la transición energética con un impulso adicional al Pacto Verde. Sus efectos positivos sobre la actividad pueden hacerse sentir a corto plazo, pero también prolongarse en el futuro con un cambio del modelo energético europeo. Aquellos Estados miembros de la UE que no quieran participar en esta estrategia económica contra los efectos del coronavirus pueden sencillamente renunciar a los estímulos canalizados a través del Pacto Verde. Sin embargo, hay quienes argumentan que los planes de estímulo verdes no son la única respuesta económica posible, especialmente a corto plazo. Argumentan que este énfasis en la transición energética tiene que medirse frente a otros objetivos de recuperación relacionados con el impacto sanitario y social de la crisis, así como al papel de las políticas macroeconómicas y otras políticas sectoriales.

Finalmente, el coronavirus ha irrumpido en el proceso de gobernanza climática en un momento crítico. La ciencia llama a aumentar la ambición, pero la atención política está centrada a corto plazo en luchar contra la pandemia. Además, se pierde el face-to-face buzz de la diplomacia climática en 2020 y se retrasan citas importantes. Sin embargo, esta menor visibilidad del clima en la agenda política podría usarse para que se adopte legislación climática más robusta, en la UE y España, incluyendo comités científicos de cambio climático a los que tengan que responder los gobiernos. Las reducciones temporales en las emisiones de gases de efecto invernadero y en la contaminación del aire no deben hacernos pensar que solucionaremos el cambio climático sin cambiar nuestro modelo de desarrollo y nuestra forma de vida. Si seguimos ignorando las advertencias de la ciencia del clima, como hemos ignorado hasta la fecha las advertencias relativas a la necesidad de prepararnos para una pandemia, lo haremos poniendo en peligro nuestro bienestar y el de generaciones venideras.

\section{Referencias bibliográficas}

Banco de España (2020). Escenarios macroeconómicos de referencia para la economía española tras el COVID-19 [Boletín Económico n. ${ }^{\circ}$ 2].

Birol, F. (2020, March 14). Put clean energy at the heart of stimulus plans to counter the coronavirus crisis. IEA Commentary.

Bloomberg New Energy Finance (BNEF). (2019). Battery pack prices fall as market ramps up with market average at $\$ 156 / \mathrm{kWh}$ in 2019. BNEF.

Callaway, E., Cyranoski, D., Mallapaty, S., Stoye, E., \& Tollefson, J. (2020, March 19). The coronavirus pandemic in five powerful charts. Nature.

Cass, N., \& Faulconbridge, J. (2016). Commuting practices: New insights into modal shift from theories of social practice. Transport Policy, 45, 1-14.

Cheng, V. C. C., Lau, S. K. P., Woo, P. C. Y., \& Yuen, K. Y. (2007). Severe acute respiratory syndrome coronavirus as an agent of emerging and reemerging infection. Clinical Microbiology Review, 20(4), 660-694.

Cohan, D. (2020, March 15). Coronavirus crisis opens new paths toward clean energy. The Hill.

Coltura (s. f.). Gasoline vehicle phaseout advances around the world. Coltura.

Comisión Europea (2019a). Cambio Climático. Special eurobarometer 490.

Comisión Europea (2019b). United in delivering the Energy Union and Climate Action - Setting the foundations for a successful clean energy transition. COM(2019) 285 final.

Comisión Europea (2019c, June 18). EU Green Bond Standard. European Commission.

Comisión Europea (2020). Proposal for a Regulation of the European Parliament and of the Council Establishing the Framework for Achieving Climate Neutrality and Amending Regula- 
tion (EU) 2018/1999 (European Climate Law). COM(2020) 80 final, 2020/0036 (COD).

Consejo Europeo (2020). Reunión extraordinaria del Consejo Europeo, 17 a 21 de julio de 2020.

Convención sobre la Diversidad Biológica (2020). Processes and meetings.

Demertzis, M., Sapir, A., Tagliapietra, S., \& Wolf, G. B. (2020, March). An effective economic response to the coronavirus in Europe. Bruegel Policy Contribution, (6).

Ecopost (2020, 29 de abril). Finanzas sostenibles: Las herramientas para una recuperación económica resiliente y justa. Ecopost.

Escribano, G. (2020). Conjeturas energéticas para 2020: geopolíticas del petróleo, el gas y el Pacto Verde Europeo. Análisis del Real Instituto Elcano (ARI), (7), 1.

Esteban, M., \& Lázaro, L. (2020). The alignment of Chinese financing with the Paris Agreement: Propaganda, aspiration or reality? Comunicación para Asia-Europe Sustainable Connectivity Scientific Conference (AESCON).

EU Technical Expert Group on Sustainable Finance (2019, September). Financing a sustainable European economy - Report on benchmarks.

EU Technical Expert Group on Sustainable Finance (2020, March). Taxonomy: Final report of the Technical Expert Group on Sustainable Finance.

Euractiv (2020, March 17). Czech PM urges EU to ditch Green Deal amid virus. Euractiv.

European Council (2020). Special meeting of the European Council (17, 18, 19, 20 and 21 July 2020) - Conclusions. EUCO 10/20.

Frankfurt School-UNEP. (2019). Global Trends in Renewable Energy Investment.

Fankhauser, S., Averchenkova, A., \& Finnegan, J. (2018). 10 years of the UK Climate Change Act. London School of Economics and Political Science, Grantham Research Institute on Climate Change and the Environment, Centre for Climate Change Economics and Policy.

Friedman, L. (2020, March 26). E.P.A., Citing coronavirus, drastically relaxes rules for polluters. The New York Times.

Gardiner, B. (2020, March 23). Coronavirus holds key lessons on how to fight climate change. Yale Environment360.

Green Recovery Alliance (2020, April 16). Reboot and reboost our economies for a sustainable future - call for mobilisation.

Grupo Español para el Crecimiento Verde (2020, 19 de abril). El GECV urge una recuperación económica verde [nota de prensa].

Hallack, M. y Yepez, A. (2020, 27 de marzo). Retos del sector de energía con la crisis del Coronavirus. Blog del BID.

Harvey, F. (2020, March 2). Vital Cop26 climate talks could be derailed by coronavirus. The Guardian.

Hepburn, C., O'Callaghan, B., Stern, N., Stiglitz, J., \& Zenghelis, D. (2020). Will COVID-19 fiscal recovery packages accel- erate or retard progress on climate change? Oxford Smith School of Entreprise and the Environment, Working Paper No. 20-02.

International Energy Agency (IEA). (2020). Renewable Energy Market Update. Outlook for 2020 and 2021. IEA Publications \& data.

International Monetary Fund (IMF). (2020, June). World Economic Outlook Update.

Ipsos (2020a, April). How does the world view climate change and Covid-19? Ipsos Global Advisor.

Ipsos (2020b, March 14). Impact of coronavirus to new car purchase in China. Ipsos News.

Khan, M. (2020, April 3). Dumping Europe's green ideals. Financial Times Brussels Briefing.

Lázaro, L. (2020, 24 de febrero). Cambio climático 2020: ciencia, tras el maratón COP 25, el Pacto Verde Europeo y legislación climática en España. Análisis del Real Instituto Elcano (ARI), (14), 1.

Lázaro, L., González Enríquez, C. y Escribano Francés, G. (2019, 24 de septiembre). Los españoles ante el cambio climático. Encuesta del Real Instituto Elcano.

Manuell, R. (2020, March 18). Clean energy transition will take coronavirus hit. ICIS VIEW.

Mars, A. y Planelles, M. (2020, 22 de septiembre). China promete en la ONU un plan para alcanzar la neutralidad de carbono en 2060. El País.

Matsumura, W., \& Adam, Z. (2019). Fossil fuel consumption subsidies bounced back strongly in 2018. International Energy Agency (IEA) Commentary.

Mazzucato, M. (2020, March 18). The Covid-19 crisis is a chance to do capitalism differently. The Guardian.

Meidan, M. (2020, March). Geopolitical shifts and China's energy policy priorities. The Oxford Institute for Energy Studies (OIES) Comment.

Mileu (2020, March). Phasing-out sales of internal combustion engine vehicles. Scoping study by Milieu for Transport \& Environment, final report.

Millán, L., Shankleman, J., \& Rathi, A. (2020, March 17). An economic crash will slow down the electric vehicle revolution... but not for long. Bloomberg Green.

Ministerio de Ecología y de Medio Ambiente de la República Popular China (2019). China's policies and actions for addressing climate change (2019).

Ministerio de Hacienda (2020). Programa Nacional de Reformas 2020.

Ministerio para la Transición Ecológica y el Reto Demográfico (MITECO). (2020). Plan Nacional Integrado de Energía y Clima 2021-2030.

Mora Álvarez, D. F., Kitzing, L., Soysal, E. R., Steinhilber, S., del Río, P., Wigand, F., Klessmann, C., Tiedemann, S., Blanco, A. L. A., Welisch, M., Kreiß, J., Fitch-Roy, O., \& 
Woodman, B. (2017, December). Auctions for renewable energy support - Taming the beast of competitive bidding. Final report of the AURES Project, Report D9.2.

Morrow, D., \& Ma, K. (2020, March 12). Coronavirus, oil prices and ESG: three takeaways for investors. Sustainalytics.

Ontiveros, E. (2020, 19 de marzo). Píldoras de actualidad COVID19 - El impacto del COVID19 en la economía mundial y en la economía española. Analistas Financieros Internacionales-Afi.

Parkin, B., Wilkes, W., \& Carr, M. (2020, March 6). Germany touts green stimulus in post Covid-19 policy push. Bloomberg Green.

Paun, A. (2020, March 27). ESG stocks did best in COVID-19 slump. Climate and sustainable investments outperformed as pandemic struck. HSBC.

Pickard, J., Giles, C., \& Hodgson, C. (2020, March 18). Travel clampdown threatens Glasgow climate summit. Financial Times.

Plumer, B., \& Fountain, H. (2020, March 11). Coronavirus and climate change. The New York Times.

Poortinga, W., Fisher, S., Böhm, G., Steg, L., Whitmarsh, L., \& Ogunbode, C. (2018). European Attitudes to Climate Change and Energy: Topline Results from Round 8 of the European Social Survey. ESS.

Presidencia Croata del Consejo Europeo (2020, March 6). Submission by Croatia and the European Commission on behalf of the European Union and its Member States. Subject: longterm low greenhouse gas emission development strategy of the European Union and its Member States.

Real Instituto Elcano (2020, abril). Barómetro del Real Instituto Elcano - 41'a Oleada BRIE.

Reuters (2019, August 22). China mulls ban on gasoline cars in some regions. Automotive News.

Schulz, F. (2020, September 11). EU lawmakers up the ante, vote for $60 \%$ climate target for 2030. Euractiv.
Silva, G., \& Di Serios, L. C. (2016). The sixth wave of innovation: are we ready? RAI Revista de Administração e Inovação, 13(2), 128-134.

Simon, F. (2020, April 16). LEAKED: full list of delayed European Green Deal initiatives. Euractiv.

Steinberg, F. (2020, 19 de marzo). Ante la incertidumbre radical. El País.

Storper, M., \& Venables, A. J. (2004). Buzz: face-to-face contact and the urban economy. Journal of Economic Geography, 4(4), 351-370.

Stromsta, K. E. (2020, March 15). For wind and solar sectors, biggest coronavirus risk may be a damaged economy. GTM.

Temple, J. (2020, March 9). Why the coronavirus outbreak is terrible news for climate change. MIT Technology Review.

Tocci, N. (2020, March 20). International order and the European project in times of COVID19. IAI Commentaries.

Vetter, D. (2020, March 13). How coronavirus makes the case for renewable energy. Forbes.

Viscidi, L., \& Graham, N. (2020, March 27). Pandemic and Price Collapse: Impacts for Energy in Latin America. The Dialogue.

World Economic Forum (WEF). (2020). The Global Risks Report 2020.

World Meteorological Organisation (WMO). (2020a). United in Science 2020.

World Meteorological Organisation (WMO). (2020b). WMO Statement on the State of the Global Climate in 2019. WMO, (1248).

Wu, X., Nethery, R. C., Sabath, B. M., Braun, D., \& Dominici, F. (2020). A national study on long-term exposure to air pollution and COVID-19 mortality in the United States. Harvard University. Also in medRxiv. https://doi. org/10.1101/2020.04.05.20054502 